\title{
Chapter 3 \\ The Application of Urban Building Energy Modeling in Urban Planning
}

\author{
Shimeng Hao and Tianzhen Hong
}

\begin{abstract}
Urban energy planning plays an essential role in guiding human settlements, from a neighborhood scale to a megacity scale, to a sustainable future. It is particularly challenging to integrate energy planning into the urban planning process, considering the urban system's complexity, multi-objective decision making, and multi-stakeholder involvement. In this context, recent years have witnessed a significant development of urban building energy modeling (UBEM). With a trend toward performance-based urban planning, there is a rising need to introduce proper UBEM tools into the different planning phases. The main objective of this chapter is to provide an overview of the UBEM tools across different urban planning phases, as well as to discuss to what extent these tools could provide decision-making support to stakeholders. The chapter starts with a brief discussion on emerging energyrelated issues in urban development and why the conventional planning approach needs the integration of modeling tools to provide a quantitative evaluation to better respond to these new challenges. The state of the art of UBEM also is reviewed, followed by a description of the applications and limitations in different planning phases. Finally, several challenges and opportunities regarding energy-modelingassistance urban planning are discussed.
\end{abstract}

Keywords Urban energy planning - Urban systems · Urban planning process · Energy efficiency $\cdot$ Sustainability

\footnotetext{
S. Hao $(\bowtie)$

Building Technology and Urban Systems Division, Lawrence Berkeley National Laboratory, Berkeley, CA, USA

Beijing University of Civil Engineering and Architecture, Beijing, People's Republic of China e-mail: haoshimeng@bucea.edu.cn

T. Hong

Building Technology and Urban Systems Division, Lawrence Berkeley National Laboratory, Berkeley, CA, USA

e-mail: thong@lbl.gov
} 


\subsection{Introduction}

Contemporary cities are composed of complex and interrelated systems. With unprecedented rapid global urbanization and booming urban technologies, not to mention climate change and environmental issues, the enormous challenges faced by a modern urban planner are far beyond those of the ancient Greek urban planner Hippodamus's imagination (Burns, 1976). The United Nations (UN) predicts that by 2050, 6.4 billion people will be living in urban areas, making up $70 \%$ of the world population (UN, 2014). Today's cities are endeavoring to be sustainable, and energy is always an inevitable topic of prime importance.

Several positive and negative impacts are associated with urbanization from an energy perspective. On the one hand, a compact city form will promote energy efficiency and urban service quality compared with a low-density sprawling urban form. A growing number of researches have shown that the optimization of urban density, function allocation, building configuration, and morphology, as well as other urban form parameters, can positively influence energy demand and carbon dioxide emissions (Ratti, Baker, \& Steemers, 2005; Rode, Keim, Robazza, et al., 2014; Salat, 2009). On the other hand, the increasingly densified metropolitan area suffers from the urban heat island (UHI) effect and is more vulnerable to extreme climatic events such as heat waves, rainstorm waterlogging, wildfires, and power outages.

The emerging next-generation urban energy technologies—such as district energy networks (DEN) (Rismanchi, 2017), smart grids, decentralized energy systems, and net-zero energy buildings (NZEB) - offer opportunities to tackle these problems. The district energy system is characterized by utilizing multi-energy sources and providing heating, cooling, and electricity to local neighborhoods with a combination of district energy plants, energy storage systems, and distribution systems. Compared with conventional heating and cooling systems, the benefits of district energy system include relatively higher overall efficiency, lower annual cost for customers, more flexibility in integrating locally available renewable energy resources (such as solar energy, biomass, and geothermal), and a significant potential for greenhouse gas (GHG) reductions (Rismanchi, 2017; Schweiger, Heimrath, Falay, et al., 2018). Correspondingly, for system design and optimization, challenges are arising: the drastic fluctuation from centralized and individual renewable energy generators, the complexity of user behavior from the building and transportation sectors, dynamic energy storage from daily to seasonal temporal scale, and more. The application of district energy modeling tools can bring considerable advantages to support design assessment, as well as operational optimization of the system (Schweiger et al., 2018).

Nonetheless, the traditional empirical evidence-based urban planning scheme often fails to support the effective integration of these technologies into urban (re) developments (Cajot, Peter, Bahu, et al., 2017; Markus, Avci, Girard, Keim, \& Peter, 2009; Strasser, 2015). With the trend of performance-based and, more specifically, energy-based urban planning approaches, which seek to optimize or even 
generate urban morphologies from an energy perspective, a strong need arises to introduce proper urban energy modeling and simulation tools into various planning phases (Van Beuzekom, Gibescu, \& Slootweg, 2015). In this context, recent years have witnessed a significant development of urban building energy modeling (UBEM). This chapter provides an overview on how and to what extent these UBEM tools could support urban planning by addressing some key questions, including:

- What are the new requirements of urban planning from the energy perspective?

- What are the specific applications of UBEM tools across various urban planning phases and scales?

- How can stakeholders benefit from the integration of UBEM tools into urban planning process?

- What are the challenges and opportunities of energy modeling-assisted urban planning?

\subsection{The Role of Energy Modeling in Urban Planning}

\subsubsection{New Requirements of Urban Planning from the Energy Perspective}

Urban planning plays a vital role in guiding a human settlement, from the neighborhood scale to the megacity scale, to a better future (Peter \& Yang, 2019). In line with the concept of sustainable development, the significance of energy planning reveals increasing coordination with master plans, either integrated with the general comprehensive plan or as an independent specialized plan. Although the specific planning approaches and components may be extremely varied from country to country, due to the different planning law frameworks and urban development stages, some common trends and barriers in urban planning have emerged (Geneletti, La Rosa, Spyra, \& Cortinovis, 2017; Torabi, Delmastro, Corgnati, \& Lombardi, 2017).

In recent years, the paradigm of energy system planning has shifted from the traditional, supply-side energy policy and management to a more demand-side approach, focusing on the district level (Keirstead, Jennings, \& Sivakumar, 2012; Nageler, Koch, Mauthner, et al., 2018). The application of renewable energy sources within the smart grid and microgrids has increased the diversities in energy supply and its business models. Decentralized energy solutions such as on-site power generation can transform an individual building or household from an energy consumer to an energy producer. Consequently, the energy flows in this new-generation system are multi-directional and change dynamically, which brings tremendous challenges to energy planning (Ma, Ren, Zhao, et al., 2020). In line with the concepts of distributed energy resources and the District Energy System (DES), the task of developing more accurate energy load forecasting models with higher spatiotemporal resolutions becomes increasingly crucial. 


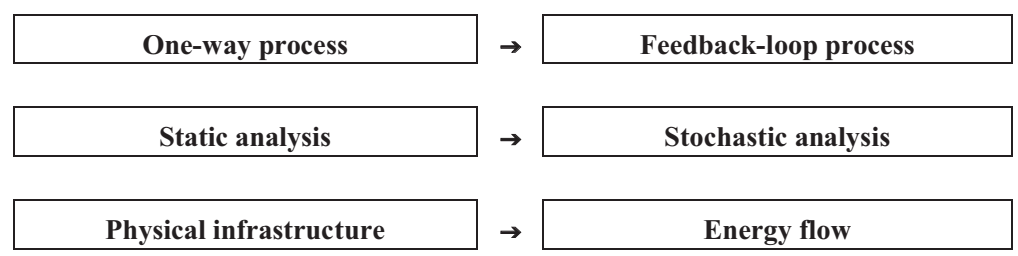

Fig. 3.1 Three main trends in urban energy planning

Furthermore, the energy concerns in sustainable urban planning are not solely addressable through the urban energy infrastructure alone (Li, Quan, \& Yang, 2016; Madlener \& Sunak, 2011). Urban building energy consumption is highly coupled with other urban systems and sectors, including but not limited to transportation, land-use patterns, and urban forms. However, conventional urban energy system planning is often conducted at the end of the planning phase, to select proper energy supply methods, when most of the decisions crucial to energy consumption have already been made. Under the traditional planning framework, the socioeconomic issues and quality of urban services are the main topics, while the role of energy planning is relegated to just supporting those "more important" issues (Cajot et al., 2017). Moreover, urban planners and other decision-makers typically rely on precedent projects and experience, which depends more on qualitative analyses than quantitative assessments (Ferreira, Lage, Doraiswamy, et al., 2015).

In general, three trends can be observed for urban energy planning (see Fig. 3.1): (1) from a one-way process to a feedback-loop process, which improves consideration of the interactive effects among urban systems and processes, (2) from static analysis to stochastic analysis, which enables robust design that considers uncertainty in weather and climate conditions as well as dynamic energy demand and supply, and (3) from physical infrastructure to energy flow, which abstracts and represents urban systems as urban metabolism in terms of materials and energy flows in urban areas.

\subsubsection{Introduction to Urban Building Energy Modeling (UBEM)}

Urban building energy modeling (UBEM) tools have a high potential to strengthen the integration of the multidisciplinary aspects of energy issues in the urban planning process (Hong et al., 2020; Reinhart \& Cerezo Davila, 2016). UBEM is widely used in the evaluation of energy consumption between alternative urban forms, optimization of energy management from both the energy supply and demand sides, and scenario analysis of energy-saving potentials of technologies (Lombardi, Abastante, Torabi, \& Toniolo, 2017; Van Beuzekom et al., 2015; Zanon \& Verones, 2013).

Based on modeling approaches (see Fig. 3.2), UBEM can be classified into "topdown" models and "bottom-up" models (Reinhart \& Cerezo Davila, 2016; Swan \& 


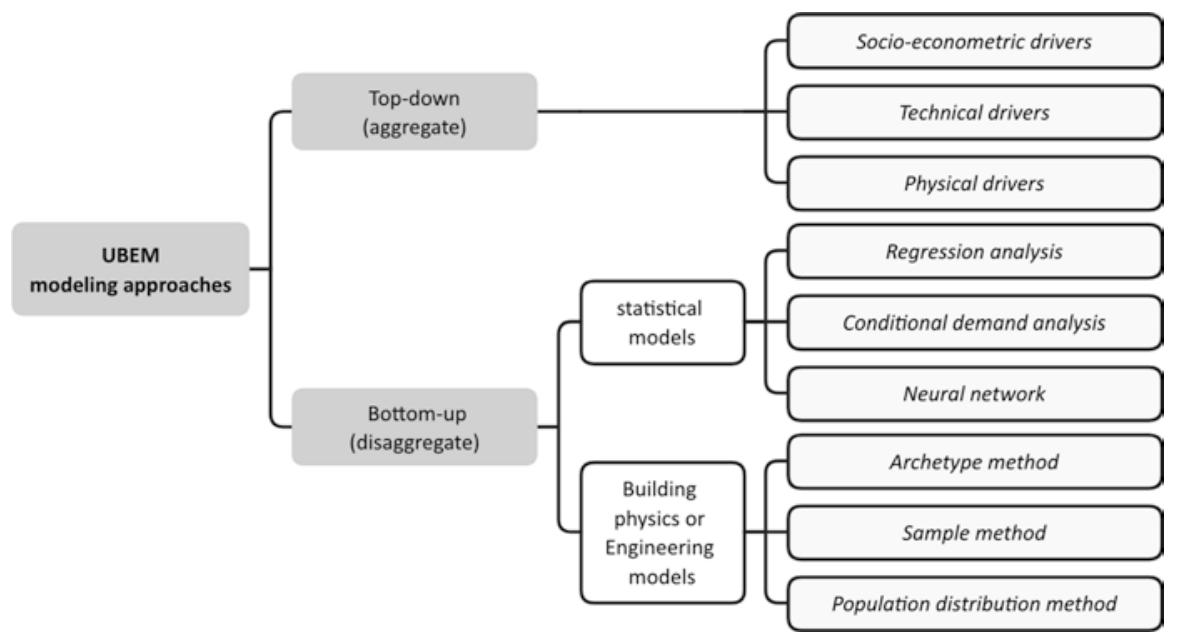

Fig. 3.2 Modeling approaches of UBEM

Ugursal, 2009; Kavgic et al., 2010). The top-down approach is characterized by aggregating input data and results at urban and regional levels without considering spatial or temporal details. It has been considered to be suitable in long-term and large-scale energy policy estimation; however, it has obvious limitations when performing energy analysis for a group of building in the urban context (Hong \& Luo, 2018). Bottom-up models provide energy insights down to the individual building level, and these are subdivided into statistical-based models and physics-based models. The statistical models establish correlations between the actual energy use and driving drivers such as building stock characteristics, local climate, and occupant behavior at a building or district level, by adopting regression analysis, conditional demand analysis, and machine learning techniques (Torabi et al., 2017). In contrast, building physics models are based on thermodynamic simulations (Aydinalp-Koksal \& Ugursal, 2008), which have been recognized as suitable for energy retrofit assessment and optimization across different spatiotemporal scales. Correspondingly, high-quality data and considerable computational efforts are essential to effectively support and generate high fidelity building physics models.

Building energy modeling at a larger scale is not simply scaling up the simulation results of individual buildings (Hong et al., 2020). Inter-building effects, including long-wave heat emission and shading, as well as heat exchange between buildings and the urban environment, can significantly influence building energy demand (Bourikas, 2016; Savić, Selakov, \& Milošević, 2014). Consequently, UBEM should take microclimate effects and interactive effects among buildings into account. In this light, a physics-based dynamic simulation method shows its predominance compared to other approaches.

Some literature thoroughly reviewed the state of the art of UBEM tools in detail (Hong et al., 2020; Li, Zhou, Cetin, et al., 2017; Torabi et al., 2017), comparing the differences in calculation approach, spatiotemporal resolution, input/output data 
format, and potential applications. Some tools, such as the Urban Modeling Interface (umi) and Grasshopper interface for CitySim (GHCitySim), were developed as plug-ins for prevailing planning and design platforms (Peronato, Kämpf, Rey, \& Andersen, 2017) (see Fig. 3.3), benefitting the integration of energy systems with urban form generation and optimization at the early planning stage. These tools usually emphasize the correlations between urban design parameters (such as block density, building geometry, and land-use allocation) and urban performances (e.g., energy efficiency, outdoor thermal comfort, energy generation potential). The simulation requirements are often simplified, while the analysis target is to obtain the tendency rather than the specific data. Therefore, they are more user friendly to planners and are suitable for early-stage planning.

In contrast, other UBEM tools emphasize the accuracy and robustness of the models, and are more dependent on high-performance computing efforts and data availability. These tools have great application potential in operational optimization and energy retrofit estimation. However, such tools require operation by professional users with urban building energy simulation backgrounds. Whether this process is conducted by an independent consultant group or professional staff within the planning team, close collaboration with urban planners is undoubtedly necessary.

Apart from the conventional stand-alone desktop applications, web-based UBEM tools have been a growing trend in recent years. Web interfaces have shown satisfactory performance in data visualization, as well as in supporting cloud computation.

The planning and research communities are coping with increasing complexities in modeling interactions among different urban systems. Many efforts have been made to promote co-simulation of UBEM and various urban system models, including (1) urban microclimate models using computational fluid dynamics (CFD) and other numerical models (Mirzaei, 2015; Toparlar, Blocken, Maiheu, \& van Heijst, 2017), (2) urban system energy models (USEM), and (3) land-use transport models (LUT), as shown in Fig. 3.3.

Interface and Visualization

Integrated Urban System Modeling

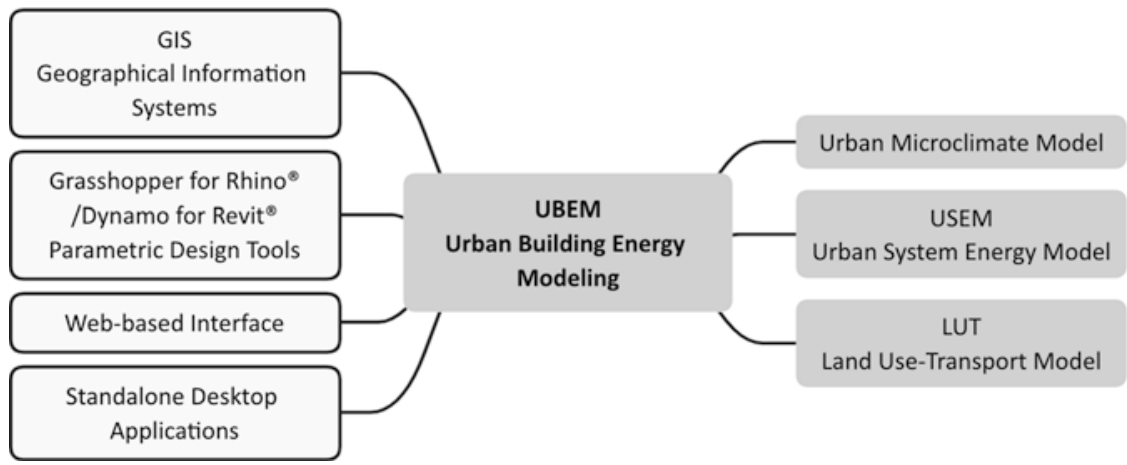

Fig. 3.3 Integration of UBEM with other urban system models and design platforms 
Energy consumption of an individual building is strongly affected by the local urban climate. Conversely, building geometry, thermal characteristics, and the operation of building equipment also influence the urban microclimate significantly (Sharmin, Steemers, \& Matzarakis, 2017). Coupling the urban microclimate model with UBEM can improve the accuracy of simulation results for both sides. Urban system energy models are widely adopted in the field of designing and optimizing energy networks and systems. However, when it comes down to the district level, the application of USEM is limited due to its relatively low fidelity on demand-side estimation. UBEM and USEM approaches are combined in the latest tools to better support the planning and operation of the district energy system. Building energy models (BEM), an inherent and inseparable part of the physics-based simulation UBEM approach, also play an important role in the operation of the district energy system and building energy resilience. Dynamic BEM are capable of predicting real-time indoor environment variables and energy loads, giving control feedbacks to the district system, and providing early warnings of the most vulnerable urban areas or buildings under extreme weather events. Moreover, a great deal of energy can be saved by establishing a correlation between urban human mobility and building energy consumption. Several studies demonstrated a strong spatial dependency between energy use and location-based activities (de Casas Castro Marins \& de Andrade Roméro, 2013; Shirgaokar, Deakin, \& Duduta, 2013). In this sense, one can estimate building energy demand by using individual positional data.

The profundity of co-simulation may vary by adopting different coupling approaches. One approach is to combine the physical models and processes into one model hierarchy (Hong et al., 2020). This might be the most promising approach when the complexity of coupled physical processes is acceptable and sufficient computational resources are available. Otherwise, co-simulation frameworks could be used. By adopting such frameworks, coupled models are assigned as different simulation layers, which can be executed in parallel or series with data communication in run-time. A third approach is to run several predetermined scenarios across different models when the data quality or other conditions cannot meet the requirements.

\subsubsection{Application of UBEM in the Urban Planning Processes}

Before integrating energy considerations into the urban planning process, it is fundamental to understand that process. The urban development paradigm, as well as the urban planning scheme, undoubtedly varies from country to country, even case to case. Nevertheless, despite the different names assigned to certain planning schemes, the hierarchy and planning objectives of contemporary statutory planning systems in different countries have more in common with each other than differences (Wu, 1991; Hall \& Tewdwr-Jones, 2019). Generally speaking, the most commonly adopted planning schemes can be summarized as five phases (Cajot \& Schüler, 2018; Meskel \& Weber, 2017) (see Fig. 3.4): 


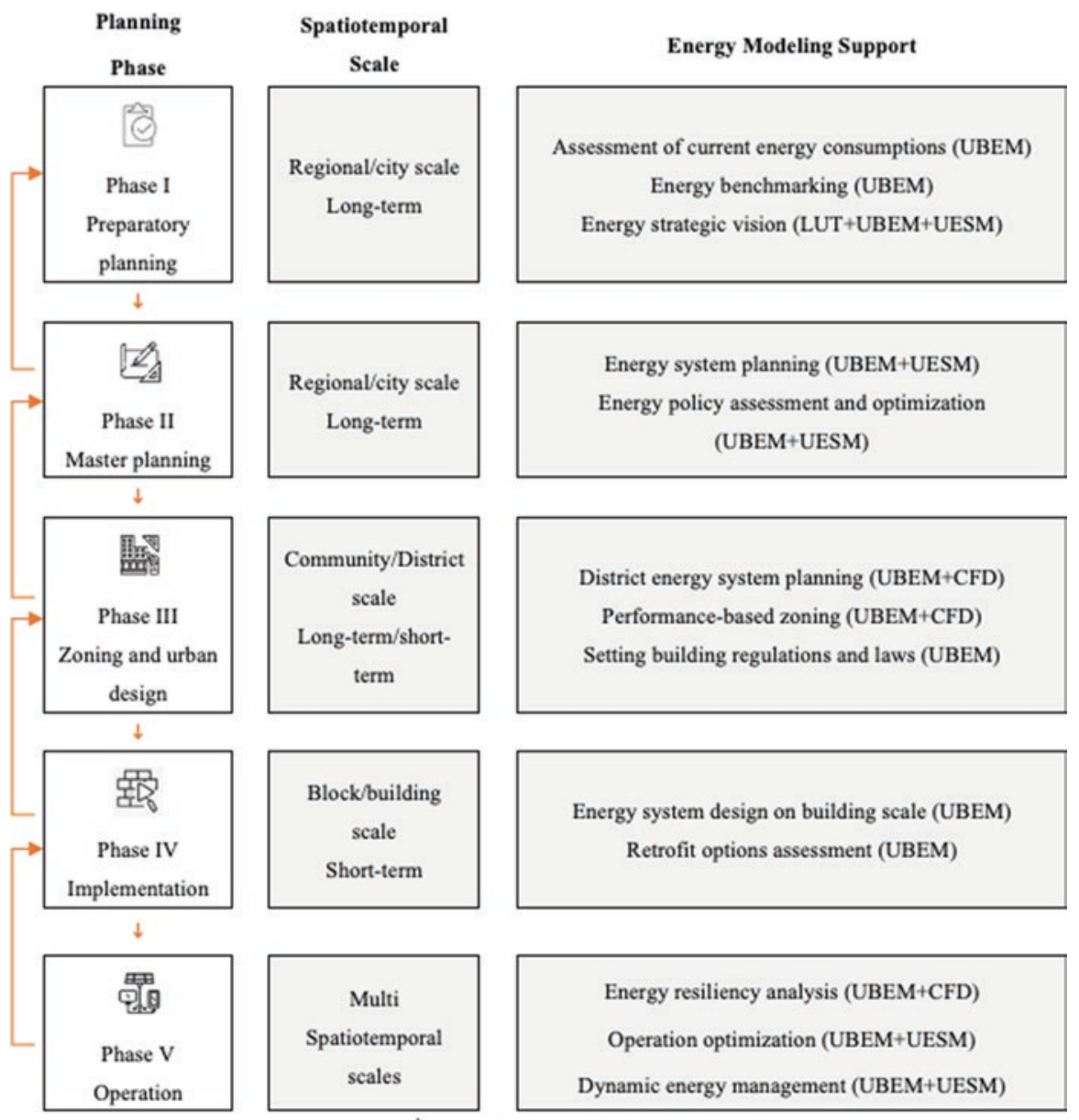

Fig. 3.4 UBEM support within a typical urban planning process

1. Preparatory planning: Identification of existing problems, definition of planning issues, and formulation of goals and visions

2. Master planning: Formulation of the evaluation framework based on the achievement of goals and objectives, generation, and assessment of alternative plans

3. Zoning and urban design: Elaboration of a comprehensive master planning at the district or community level, and formulation of a zoning plan and building regulation plan

4. Implementation: Building design and construction for the new development area or building retrofit for the transformation area in compliance with upperlevel plans, and performance optimization at individual buildings or the block level 
5. Operational: Operation of buildings, infrastructure, and services, and monitoring of energy generation and consumption

It should be noted that urban planning is not a one-way process; the outcomes of each phase should be carefully evaluated to see whether they are in full compliance with the planning objectives, and if not, adapting the present plan through a feedback loop (Schoenwandt, 2016). The planning deliverables of these phases play their roles on different temporal and spatial scales. A comprehensive general plan outlines the regional or metropolitan development vision in a relatively long term of 15-20 years (Yigitcanlar \& Teriman, 2015), whereas detailed planning schemes such as zoning ordinance and redevelopment plans on the district level are formulated for the short-term or medium-term. UBEM has the capability to cover spatial scales from dozens of buildings in a block to hundreds of thousands of buildings in an entire city, and cross-temporal scales from an hour to multiple decades. It is essential to select scale-appropriate UBEM tools to ensure the efficiency and accuracy of the simulation.

The assessment of energy aspects in urban planning is executed by introducing proper planning instruments for different planning stages (Meskel \& Weber, 2017). These instruments can be classified into two groups: specific energy planning instruments and general urban planning instruments. Specific energy planning instruments directly provide guidance on how to make decisions on energy infrastructure and management, including an urban climate and energy strategy, an energy roadmap, building regulation for energy efficiency, and so on. Conversely, general urban planning instruments, such as zoning, land use plans, transportation plans, and urban design guidelines, have an indirect yet significant influence on energy issues by shaping urban form. Accordingly, UBEM tools should be carefully selected and applied to facilitate different instruments. In the following parts of this section, the planning instruments and matching UBEM tools will be discussed in detail for each planning phase, demonstrating their viability for supporting decisions by urban planners, policymakers, and other stakeholders.

\subsubsection{Phase I: Preparatory Planning}

The pivotal tasks in the preparatory planning phase include assessment of current and forecast conditions, the development of goals and visions with full involvement of stakeholders, and the evaluation of policy and strategy feasibility by future scenario exploration analyses.

Data collection is one of the fundamental actions in Phase I (Mirakyan \& De Guio, 2013). To set up a strong support for urban system modeling, numerous energy-related data of different formats and sources should be included into the dataset, including large-scale urban spatial and geometry data (mainly imported from CityGML, GeoJSON, and other open data sources), socioeconomic and demographic data (from a census database), and meteorological data (from historical weather data or imported from Urban Weather models). However, the lack of 
high-quality and continuous data in the early planning phase has always been a major problem.

Another challenge for rational planning at this early stage is multi-objective decision making. Although planners and other decision-makers can get a clear overview of the current energy consumption level with UBEM simulation tools, more comprehensive evaluations that also account for other energy-related planning issues (such as urban growth, transportation dynamics, land use, and environmental quality) are essential for setting up future scenarios. However, in most cases, this does not seem viable, due to both the complexity and unclear mechanisms of urban systems and the limitation of the prevailing tools (Van Beuzekom et al., 2015). Nevertheless, simplified models seem to be acceptable for scenario comparisons at this early stage, for the decision making is more reliant on tendencies rather than specific data (Wilson, Danforth, Davila, \& Harvey, 2019). To enhance the collaboration of multiple stakeholders and experts in decision making, data visualization is an important feature (; Pelzer, Arciniegas, Geertman, \& Lenferink, 2015). Interfaces based on the web or planning software such as geographic information systems (GIS) and parametric design platforms have advantages in this respect.

\subsubsection{Phase II: Master Planning}

For the master planning phase, general planning objectives and strategies are further developed into a more operational and implemental design criteria. UBEM plays an important role in generating and evaluating alternative urban forms according to design criteria and objectives. Compared with Phase I, more detailed analyses with higher fidelity are required for formulating comprehensive master planning and energy system planning at a city scale. The urban form (characterized by the typology of urban blocks, land use-transportation structures, urban density, open space structures, and other factors) will be determined at this phase. Those factors highly influence demand-side energy use, as well as the potential for decentralized energy generation. Accordingly, the proper energy system aimed at securing a reliable and affordable energy supply will be established, addressing the dynamic energy demand, through coupling with urban comprehensive energy system modeling tools. By incorporating UBEM with generative design tools, it is possible to obtain tens of thousands of alternative master plans automatically, by manipulating urban form-related parameters (Wilson et al., 2019). The performance of these alternative plans can then be evaluated and clustered by machine learning methods.

In this phase, once the best alternative planning is selected, it should loop back to see whether it is compliant with the energy planning objectives and criteria defined in the former phase. If it can fulfill the evaluation requirements, the plan goes to the next process. 


\subsubsection{Phase III: Zoning and Urban Design}

At this mesoscale district level, there is significant potential in energy optimization of both the district energy system and the impact of district morphology on energy consumption (Rismanchi, 2017; Wilson et al., 2019; Wilson, Danforth, Harvey, \& Licalzi, 2018).

Advanced district energy systems, which can be composed of shared energy infrastructures, smart microgrids, and decentralized energy sources, can achieve much higher energy efficiency. A wide variety of USEM tools have been developed for planning district energy systems. The key point of a well-designed district energy system lies in the accurate forecasts of energy loads and supplies (Lake, Rezaie, \& Beyerlein, 2017), which can be achieved by coupling UBEM with USEM.

Although most research efforts have focused on the district energy system in this planning phase, performance-based zoning has attracted more attention. There is substantial evidence that building typology and urban morphology influence building energy consumption and GHG emissions ( $\mathrm{Li}$ et al., 2016). Considering the unprecedented growth rate and high increasing density of cities, traditional standards and workflows cannot adequately facilitate the timely updating of zoning regulations (Wilson et al., 2019). For new development of urban areas, the overall energy consumption of urban neighborhoods can be greatly reduced by applying the optimization of street walkability, accessibility, building function, geometry, and orientation. Detailed building characterization, including physical properties, geometry information, and energy use data, either should be used as inputs for UBEM by establishing archetypes or can be integrated and represented with CityGML Energy Application Domain Extension (Energy ADE) (Agugiaro, Benner, Cipriano, \& Nouvel, 2018). Furthermore, the productivity and economic efficiency of on-site renewable energy generation can be promoted with UBEM tools. Another strategy is to improve building energy codes and standards by considering the effect of microclimates at the district level, by co-simulation with UBEM and urban microclimate models (Abdolhossein Qomi, Noshadravan, Sobstyl, et al., 2016; Hong, Chen, Lee, \& Piette, 2016).

\subsubsection{Phase IV: Implementation}

The implementation for urban planning is by urban (re)development or energy retrofit projects in units of parcels or blocks, in compliance with zoning plan, urban design guidance, and building regulations.

For the design of new energy-efficient buildings, established simulation-aided design workflows have already been widely used in practice (Hong et al., 2018). ASHRAE Standard 209 proposed a framework of applying BEM across a building life cycle (Scott, 2019). To improve energy efficiency of a group of buildings planners can further engage UBEM into this framework, taking dynamic heat transfer between building bulks, shading effects, and outdoor thermal comfort into consideration. 
For the retrofit of existing buildings, UBEM is a powerful tool to conduct retrofit option assessment. By executing energy retrofit simulation in multiple scenarios, efficient refurbishment solutions can be promoted. Long-term energy saving potentials can be estimated along with the market aspects and economies of scale associated with the selected retrofit measures. The energy retrofit assessment can also be performed at an urban scale to improve the energy performance of agglomerate building stocks and associated service provisions (Keirstead et al., 2012). Top-down UBEMs are only capable of processing simple scenario estimations like adding or replacing a group of buildings with the same attributes. In contrast, bottom-up UBEMs are more flexible in setting energy conservation measure (ECM) scenarios with deeper complexity (Reinhart \& Cerezo Davila, 2016).

\subsubsection{Phase V: Operation and Management}

Load forecasting is critical for urban energy supply designers to estimate the energy demand and to optimize operations on a dynamic basis at a district or city scale. The empirically data-driven method, such as a nonlinear regressive model, is commonly adopted to make future load predictions using measured loads as a reference point (Powell, Sri Prasad, Cole, \& Edgar, 2014). However, its application is generally limited to specific building types and locations, with an excessive reliance on data training (Hong et al., 2020). To address this gap, there is a growing interest in using UBEM as a dynamic representation of building systems imposing constraints on the control and distribution systems (Molitor, Gross, Zeitz, \& Monti, 2014). With the application of UBEM in a real-time mode, there will be large energy-saving potential and trade-offs supported by optimal control feedback, along with continuous data monitoring of energy use and supply.

Under global climate change, urban areas suffer from increasingly frequent extreme weather events, such as heat waves, wildfires, snowstorms, and urban waterlogging. Extreme weather conditions will dramatically raise building energy demand, and an accompanying power outage could soon develop into a colossal disaster. The vulnerability degree is related to building thermal characteristics, building equipment, local microclimate, and economic conditions of the occupants. The identification of vulnerable buildings, which is vital to improving urban resiliency and safety, can be accomplished with CFD modeling and UBEM (Katal, Mortezazadeh, \& Wang, 2019). With energy resiliency analysis and building retrofit analysis, local government decision-makers can identify vulnerable buildings and prioritize high-risk populations that need to be rescued. 


\subsection{Challenges and Opportunities of Energy-Modeling-Assistance Urban Development}

\subsubsection{Challenges}

\subsubsection{Complexity of Urban Energy Systems}

Addressing energy issues at a city scale is much more challenging than at a building scale, because an urban system is composed of ill-defined, multifaceted, and dynamic problems (Cajot et al., 2017). Viewing the energy problem in a holistic and comprehensive perspective with other urban systems is crucial because it allows for both direct and indirect promotion of urban energy efficiency. Nonetheless, establishing a comprehensive integrated urban energy model is undoubtedly a challenging task because it is necessary to consider the interactions between multiple and diverse urban systems in a nonlinear way (Reinhart \& Cerezo Davila, 2016).

Apart from the technical challenges presented by the coupling and co-simulating of multi-physics urban system models (such as architecting simulation layers, runtime data exchange, and synchronization control), the main obstacle is the lack of fundamental studies on urban system interdependencies. There are future research opportunities in urban science studies. The research community should not only focus on narrowly defined urban system components but also put more effort into the interconnected influencing mechanisms among them.

\subsubsection{Multi-objective Decision Making}

Urban planning is a multi-objective decision-making process that needs the strong intellectual engagement of planners, policymakers, community and utility representatives, and related professions. The stakeholders involved and their conflict of interests are much more than a building design process. Participatory planning can be a lengthy process, requiring considerable human and financial resources. Most of the time and effort is spent on identifying shared benefits, reaching agreement on development goals, and evaluating the future influences of a specific policy. A successful, collaborative decision-making process should be based on communication of extensive information and sufficient data support. Aiming at facilitating effective stakeholder engagement and providing actionable insights from a mass volume of data, especially for non-specialist participants, there is a strong need of development of decision-making tools integrated with simulation and visualization techniques. 


\subsubsection{Limitations of the Modeling Approaches}

To avoid the "garbage-in, garbage-out" problem, a well-performing model relies on a high-quality dataset; however, that such a dataset is not always available in every case. Oversimplified archetypes and decade-old weather datasets, for instance, inevitably result in a large inaccuracy of simulation results. On the other hand, a comprehensive model with high fidelity on an urban scale is prohibitively resourceand time-consuming. In this light, it is critical to find the balance between the necessary level of detail and the computability of the model. Adapting proper spatial and temporal resolutions according to distinctive modeling purposes is essential. Further challenges exist in model calibration and result-validation work, which are limited by the lack of large-scale measurements of urban energy data.

\subsubsection{Opportunities}

\subsubsection{District-Level Energy Technologies}

District energy networks offer many economic and environmental benefits with excellent system flexibility (Powell et al., 2014). In addition to the high efficiency of district-level energy generators, such as combined heat and power (CHP) plants and heat recovery steam generators (HRSGs), they also take advantage of supply and demand diversities on a dynamic basis (Powell et al., 2014). An intelligent operation can be achieved through dynamic optimization with UBEM by providing more accurate electric, cooling, and heating load forecasting to the control system than an empirical black-box approach to forecasting (Rismanchi, 2017).

\subsubsection{Economies of Scale}

Economies of scale exist in urban development and redevelopment activities. There is a "minimum efficient scale" for construction and retrofit projects (such as a smallscale power plant, photovoltaic panel installation, or thermal energy storage), which refers to the scale point of maximum investment efficiency. Take building energy conservation projects, for instance: the evaluation of building retrofit opportunities is not limited to the energy-saving potential of certain energy-efficiency upgrades; it is also necessary to include cost-effectiveness, payback year, project scale, business model, and socioeconomic affordabilities. Applying UBEM coupling with a microeconomics model can maximize system efficiency while minimizing socioeconomic and environmental costs. 


\subsubsection{Computational Technology and Big Data}

The advancement of computational and data technologies, including artificial intelligence, machine learning algorithms, urban sensing technologies, cloud computing, and Internet of Things (IoT), offers promising opportunities to introduce UBEM into the urban planning practice. Data streams from urban energy utilities, smart power grids, transportation infrastructures, and buildings are obtained by continuous monitoring, providing data sources for model setups and model calibration. Large-scale data centers and internet technology make cloud computing more feasible as an affordable and accessible service. Equipped by this substantial improvement of computational efforts, modeling approaches not only can support decision making for urban planning but also can be used for urban management by making minute-to-minute operational decisions, contributing to shape a digital twin for a smart city.

\subsection{Concluding Remarks}

A rational urban planning process needs the support of evidence-based and quantitative decision-making tools. It is a necessary step to embrace energy modeling and analyses in the early planning stages and consistently provide feedback to keep up with evolving energy challenges (Salat, 2009). Urban building energy modeling (UBEM) is a powerful tool with great application potential in the five general urban planning phases, namely: preparatory planning, master planning, zoning and urban design, implementation, and operational. UBEM coupled with other urban system models can inform decision-makers and stakeholders for energy policy formulation, urban (re)development projects, and the intelligent operation of cities. It can provide informative and well-visualized results of end-use energy auditing and benchmarking, energy demand forecasting, building retrofit assessment, urban thermal resiliency analysis, and district energy system operation and optimization. Following a deepening understanding of the correlation between urban form and energy consumption, the energy-performance-driven planning approach is emerging, and is expected to be adopted for broad application in the future (Li et al., 2016; Naboni, Natanian, Brizzi, et al., 2019).

Corresponding to the complexity of the urban system, a promising application of UBEM is enabled by high-quality data feeding and synergism with other urban system models, such as urban system energy models, urban climate models, and land use and transportation models, as well as decision-making models and microeconomics models. Balancing the model fidelity and complexity according to the purpose of different planning stages is essential. The explosive development of big data and cloud computing technologies provides opportunities to solve data availability and computing resources problems. Promoting the standardization of data formats, terminologies, and modeling approaches among modeling and planning communities will benefit UBEM development. 
Last but not least, new planning approaches that support the integration of energy issues should be developed in practice. Ideally, a supportive planning framework should involve energy concerns from a very early planning stage and form a feedback loop. A UBEM tool developed with an interface or as a plug-in of prevailing design tools, such as GIS and parametric design tools, would be beneficial to facilitate a broad application of models by planners and designers in practice. An optimal data visualization will further enhance stakeholder involvement in the planning process. Altogether, it can be imagined that digital twins of urban systems, powered by real-time sensing, artificial intelligence, big data and analytics, modeling and simulation, and 3D GIS integrated visualization will address many challenges of urban planning, design, and operation, and unlock the potential for holistic integration of multisector dynamics to achieve optimal energy efficiency, demand flexibility, and resilience of the urban environment.

\section{References}

Abdolhossein Qomi, M. J., Noshadravan, A., Sobstyl, J. M., et al. (2016). Data analytics for simplifying thermal efficiency planning in cities. Journal of the Royal Society Interface, 13, 20150971. https://doi.org/10.1098/rsif.2015.0971

Agugiaro, G., Benner, J., Cipriano, P., \& Nouvel, R. (2018). The Energy Application Domain Extension for CityGML: Enhancing interoperability for urban energy simulations. Open Geospatial Data. Software Stand, 3(1), 139. https://doi.org/10.1186/s40965-018-0042-y

Aydinalp-Koksal, M., \& Ugursal, V. I. (2008). Comparison of neural network, conditional demand analysis, and engineering approaches for modeling end-use energy consumption in the residential sector. Applied Energy, 85, 271-296.

Bourikas, L. (2016). Microclimate adapted localised weather data generation: Implications for urban modelling and the energy consumption of buildings. University of Southampton, Doctoral thesis. https://eprints.soton.ac.uk/412948/.

Burns, A. (1976). Hippodamus and the planned city. Historia: Zeitschrift Für Alte Geschichte, 25(4), 414-428.

Cajot, S., Peter, M., Bahu, J. M., et al. (2017). Obstacles in energy planning at the urban scale. Sustainable Cities and Society, 30, 223-236. https://doi.org/10.1016/j.scs.2017.02.003

Cajot, S., \& Schüler, N. (2018). Urban energy system planning: Overview and main challenges. In U. Eicker (Ed.), Urban energy systems for low-carbon cities (pp. 19-49). Cambridge, MA: Academic. https://doi.org/10.1016/B978-0-12-811553-4.00001-9

de Casas Castro Marins, K. R., \& de Andrade Roméro, M. (2013). Urban and energy assessment from a systemic approach of urban morphology, urban mobility, and buildings: Case study of Agua Branca in Sao Paulo. Journal of Urban Planning and Development, 139, 280-291.

Ferreira, N., Lage, M., Doraiswamy, H., et al. (2015). Urbane: A 3D framework to support data driven decision making in urban development. In Proceedings of the 2015 IEEE Conference on Visual Analytics Science and Technology (VAST), 25-30 October 2015. Chicago, IL, USA: IEEE.

Geneletti, D., La Rosa, D., Spyra, M., \& Cortinovis, C. (2017). A review of approaches and challenges for sustainable planning in urban peripheries. Landscape and Urban Planning, 165, 231-243. https://doi.org/10.1016/J.LANDURBPLAN.2017.01.013

Hall, P., \& Tewdwr-Jones, M. (2019). Urban and regional planning. London: Routledge.

Hong, T., Chen, Y., Lee, S. H., Hoon Lee, S., \& Piette, M. A. (2016). CityBES: A web-based platform to support city-scale building energy efficiency. In Proceedings of the 5th Int 
Urban Comput Workshop, 14 August 2016. San Francisco, CA, USA: IEEE. https://doi. org/10.1145/12345.67890

Hong, T., Chen, Y., Luo, X., et al. (2020). Ten questions on urban building energy modeling. Building and Environment, 168, 106508. https://doi.org/10.1016/j.buildenv.2019.106508

Hong, T., Langevin, J., \& Sun, K. (2018). Building simulation: Ten challenges. Building Simulation, 11, 871-898. https://doi.org/10.1007/s12273-018-0444-x

Hong, T., \& Luo, X. (2018). Modeling building energy performance in urban context. In 2018 Proceedings of the building performance analysis and SimBuild conference, 26-28 September 2018. Chicago, IL, USA: ASHRAE and IBPSA-USA.

Katal, A., Mortezazadeh, M., \& Wang, L. (2019). Modeling building resilience against extreme weather by integrated CityFFD and CityBEM simulations. Applied Energy, 250, 1402-1417. https://doi.org/10.1016/j.apenergy.2019.04.192

Kavgic, M., Mavrogianni, A., Mumovic, D., et al. (2010). A review of bottom-up building stock models for energy consumption in the residential sector. Building and Environment, 45, 1683-1697.

Keirstead, J., Jennings, M., \& Sivakumar, A. (2012). A review of urban energy system models: Approaches, challenges and opportunities. Renewable and Sustainable Energy Reviews, 16, 3847-3866. https://doi.org/10.1016/j.rser.2012.02.047

Lake, A., Rezaie, B., \& Beyerlein, S. (2017). Review of district heating and cooling systems for a sustainable future. Renewable and Sustainable Energy Reviews, 67(C), 417-425.

Li, W., Zhou, Y., Cetin, K., et al. (2017). Modeling urban building energy use: A review of modeling approaches and procedures. Energy, 141, 2445-2457. https://doi.org/10.1016/j. energy.2017.11.071

Li, Z., Quan, S. J., \& Yang, P. J. (2016). Energy performance simulation for planning a low carbon neighborhood urban district: A case study in the city of Macau. Habitat International, 53, 206-214. https://doi.org/10.1016/j.habitatint.2015.11.010

Lombardi, P., Abastante, F., Torabi, M. S., \& Toniolo, J. (2017). Multicriteria spatial decision support systems for future urban energy retrofitting scenarios. Sustainable Cities and Society, 9 , 1252. https://doi.org/10.3390/su9071252

Ma, R., Ren, B., Zhao, D., et al. (2020). Modeling urban energy dynamics under clustered urban heat island effect with local-weather extended distributed adjacency blocks. Sustainable Cities and Society, 56, 102099. https://doi.org/10.1016/j.scs.2020.102099

Madlener, R., \& Sunak, Y. (2011). Impacts of urbanization on urban structures and energy demand: What can we learn for urban energy planning and urbanization management? Sustainable Cities and Society, 1, 45-53. https://doi.org/10.1016/j.scs.2010.08.006

Markus, P., Avci, N., Girard, S., Keim, C., \& Peter, M. (2009). Energy demand in city regions Methods to model dynamics of spatial energy consumption. In Act! Innovate! Deliver! Reducing energy demand sustainably, ECEEE 2009 Summer Study Proceedings on energy efficiency 1-6 June 2009. La Colle sur Loup: ECEEE.

Meskel, E., \& Weber, P. (2017). Review of instruments and tools used for energy and urban planning in Amsterdam/Zaanstad, Berlin, Paris, Stockholm, Vienna, Warsaw and Zagreb. In W. Schmid (Ed.), Synthesis report of Work Package 3 Instruments and tools under scrutiny. Integrative energy planning: How to support decarbonisation by integrating energy planning + urban planning. Vienna: Urban Innovation Vienna GmbH. http://www.urbanlearning.eu/fileadmin/user_upload/documents/D3.2_Synthesis_report_instruments_tools_170425_final.pdf. Accessed 22 May 2020

Mirakyan, A., \& De Guio, R. (2013). Integrated energy planning in cities and territories: A review of methods and tools. Renewable and Sustainable Energy Reviews, 22, 289-297.

Mirzaei, P. A. (2015). Recent challenges in modeling of urban heat island. Sustainable Cities and Society, 19, 200-206.

Molitor, C., Gross, S., Zeitz, J., \& Monti, A. (2014). MESCOS-A multienergy system cosimulator for city district energy systems. IEEE Transactions on Industrial Informatics, 10, 2247-2256. https://doi.org/10.1109/TII.2014.2334058 
Naboni, E., Natanian, J., Brizzi, G., et al. (2019). A digital workflow to quantify regenerative urban design in the context of a changing climate. Renewable and Sustainable Energy Reviews, 113, 109255. https://doi.org/10.1016/j.rser.2019.109255

Nageler, P., Koch, A., Mauthner, F., et al. (2018). Comparison of dynamic urban building energy models (UBEM): Sigmoid energy signature and physical modelling approach. Energy and Buildings, 179, 333-343. https://doi.org/10.1016/j.enbuild.2018.09.034

Pelzer, P., Arciniegas, G., Geertman, S., \& Lenferink, S. (2015). Planning support systems and task-technology fit: A comparative case study. Applied Spatial Analysis and Policy, 8, 155-175.

Peronato, G., Kämpf, J. H., Rey, E., \& Andersen, M. (2017). Integrating urban energy simulation in a parametric environment: A grasshopper interface for CitySim. In S. Road, L. Brotas, \& F. Nicol (Eds.), Design to thrive, Proceedings of the 33rd Passive and Low Energy Architecture (PLEA) conference, 2-5 July 2017. Edinburgh, Scotland: PLEA.

Peter, L. L., \& Yang, Y. (2019). Urban planning historical review of master plans and the way towards a sustainable city: Dar es Salaam, Tanzania. Frontiers of Architectural Research, 8, 359-377. https://doi.org/10.1016/J.FOAR.2019.01.008

Powell, K. M., Sri Prasad, A., Cole, W. J., \& Edgar, T. F. (2014). Heating, cooling, and electrical load forecasting for a large-scale district energy system. Energy, 68, 1-11. https://doi. org/10.1016/j.energy.2014.07.064

Ratti, C., Baker, N., \& Steemers, K. (2005). Energy consumption and urban texture. Energy and Buildings, 37, 762-776.

Reinhart, C. F., \& Cerezo Davila, C. (2016). Urban building energy modeling - A review of a nascent field. Building and Environment, 9(2), 176-189.

Rismanchi, B. (2017). District energy network (DEN), current global status and future development. Renewable and Sustainable Energy Reviews, 75, 571-579.

Rode, P., Keim, C., Robazza, G., et al. (2014). Cities and energy: Urban morphology and residential heat-energy demand. Environment and Planning B Planning and Design, 41, 138-162.

Salat, S. (2009). Energy loads, CO2 emissions and building stocks: Morphologies, typologies, energy systems and behaviour. Building Research and Information, 37, 598-609.

Savić, S., Selakov, A., \& Milošević, D. (2014). Cold and warm air temperature spells during the winter and summer seasons and their impact on energy consumption in urban areas. Natural Hazards, 73, 373-387. https://doi.org/10.1007/s11069-014-1074-y

Schoenwandt, W. (2016). Planning in crisis? Theoretical orientations for architecture and planning. London: Routledge.

Schweiger, G., Heimrath, R., Falay, B., et al. (2018). District energy systems: Modelling paradigms and general-purpose tools. Energy, 164, 1326-1340. https://doi.org/10.1016/J. ENERGY.2018.08.193

Scott, W. (2019). Energy simulation aided design for buildings. ASHRAE Journal, 61, 20-26.

Sharmin, T., Steemers, K., \& Matzarakis, A. (2017). Microclimatic modelling in assessing the impact of urban geometry on urban thermal environment. Sustainable Cities and Society, 34, 293-308. https://doi.org/10.1016/j.scs.2017.07.006

Shirgaokar, M., Deakin, E., \& Duduta, N. (2013). Integrating building energy efficiency with land use and transportation planning in Jinan, China. Energies, 6, 646-661. https://doi.org/10.3390/ en6020646

Strasser, H. (2015). Implementation of energy strategies in communities-from pilot project in Salzburg, Austria, to urban strategy. ASHRAE Transactions, 121, 176-184.

Swan, L. G., \& Ugursal, V. I. (2009). Modeling of end-use energy consumption in the residential sector: A review of modeling techniques. Renewable and Sustainable Energy Reviews, 13, $1819-1835$.

Toparlar, Y., Blocken, B., Maiheu, B., \& van Heijst, G. J. F. (2017). A review on the CFD analysis of urban microclimate. Renewable and Sustainable Energy Reviews, 80, 1613-1640. https:// doi.org/10.1016/j.rser.2017.05.248

Torabi, M. S., Delmastro, C., Corgnati, S. P., \& Lombardi, P. (2017). Urban energy planning procedure for sustainable development in the built environment: A review of available 
spatial approaches. Journal of Cleaner Production, 165, 811-827. https://doi.org/10.1016/j. jclepro.2017.07.142

United Nation. (2014). World urbanization prospects: The 2014 revision-highlights. New York, NY, USA: United Nations.

Van Beuzekom, I., Gibescu, M., \& Slootweg, J. G. (2015). A review of multi-energy system planning and optimization tools for sustainable urban development. In Towards future power systems and emerging technologies Proceedings of the 2015 IEEE Eindhoven PowerTech conference, 29 June - 2 July 2015. Eindhoven, Netherlands: IEEE. https://doi.org/10.1109/ PTC.2015.7232360

Wilson, L., Danforth, J., Davila, C. C., \& Harvey, D. (2019). How to generate a thousand master plans: A framework for computational urban design. In S. Rockastle, T. Rakha, C. C. Davila, D. Papanikolaou, \& T. Zakula (Eds.), Proceedings on the 10th Symposium on Simulation for Architecture and Urban design SimAUD 2019, Atlanta 07-09 April 2019. San Diego, CA, USA: The Society for Modeling and Simulation International (SCS). https://www.semanticscholar.org/paper/How-to-Generate-a-Thousand-Master-Plans\%3A-A-for-Wilson-Danforth/1 5a9f8c64dbe72689e897468dcb7fa3c872e93dc. Accessed 10 May 2020

Wilson, L., Danforth, J., Harvey, D., \& Licalzi, N. (2018). Quantifying the urban experience: Establishing criteria for performance based zoning. SimAUD Conference. In T. Rakha, M. Turrin, D. Macumber, \& S. Rockastle (Eds.), Proceedings on the 9th Symposium on Simulation for Architecture and Urban design SimAUD 2018, Dalft 5-7 June 2018. San Diego, CA, USA: The Society for Modeling and Simulation International (SCS).

Wu, L. (1991). Perspective on the structure of Chinese urban planning system — - Speaking from the progress and perplexity in the contemporary urban planning in the West City. Planning Review, 5.

Yigitcanlar, T., \& Teriman, S. (2015). Rethinking sustainable urban development: Towards an integrated planning and development process. International Journal of Environmental Science and Technology, 12, 341-352. https://doi.org/10.1007/s13762-013-0491-x

Zanon, B., \& Verones, S. (2013). Climate change, urban energy and planning practices: Italian experiences of innovation in land management tools. Land Use Policy, 32, 343-355. https://doi. org/10.1016/j.landusepol.2012.11.009

Open Access This chapter is licensed under the terms of the Creative Commons Attribution 4.0 International License (http://creativecommons.org/licenses/by/4.0/), which permits use, sharing, adaptation, distribution and reproduction in any medium or format, as long as you give appropriate credit to the original author(s) and the source, provide a link to the Creative Commons license and indicate if changes were made.

The images or other third party material in this chapter are included in the chapter's Creative Commons license, unless indicated otherwise in a credit line to the material. If material is not included in the chapter's Creative Commons license and your intended use is not permitted by statutory regulation or exceeds the permitted use, you will need to obtain permission directly from the copyright holder.

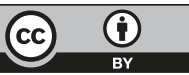

